\title{
Cognitive function during hypoglycaemia in type I diabetes mellitus
}

\author{
S PRAMMING, B THORSTEINSSON, A THEILGAARD, E M PINNER, C BINDER
}

\begin{abstract}
Neuropsychological testing was carried out in 16 insulin dependent (type I) diabetic men during four periods when mean blood glucose concentrations were (A) $6 \cdot 3($ SEM $0 \cdot 13) \mathrm{mmol} / \mathrm{l}$ (113.5 (SEM 2.3) mg/100 ml), (B) 2.9 (0.05) mmol/1 (52.3 (0.9) $\mathrm{mg}$ $100 \mathrm{ml})$, and $(C) 1.8(0.03) \mathrm{mmol} / \mathrm{l}(32.4(0.05) \mathrm{mg} / 100 \mathrm{ml})$, all measured during intravenous insulin infusion, and (D) 6.1 $(0.13) \mathrm{mmol} / \mathrm{l}(109.9(2.3) \mathrm{mg} / 100 \mathrm{ml})$, measured after intravenous glucose. The total neuropsychological test score decreased between periods $A$ and $B, A$ and $C$, and $B$ and $C$, whereas improvement occurred between periods $C$ and $D$ (all $\mathbf{p}<\mathbf{0 . 0 2}$ ). These results were not due to changes in individual subjects alone but were consistent for the whole group. During hypoglycaemia there were changes in the patients' estimates of elapsed time, which were underestimated at period $C$ as compared with the estimates at periods $A, B$, and $D$ (all $p<0 \cdot 05$ ). None of the 16 patients noticed symptoms of hypoglycaemia at period $A$ or $B, 12$ reported symptoms at $C$, and one at $D$.

Patients with type I diabetes may show a deterioration in neuropsychological skills during periods of asymptomatic subnormal or hypoglycaemic blood glucose concentrations.
\end{abstract}

\section{Introduction}

When new end points are proposed for a course of treatment the balance of risk and benefit is likely to change. Intensified insulin treatment aims at achieving near to physiological blood glucose concentrations. Since oscillations in glycaemia persist owing to the nature of subcutaneous insulin administration an increased frequency of hypoglycaemia might be expected. ${ }^{12} \mathrm{Hypoglycaemia}$ is traditionally described in terms of symptoms and signs, but the

Steno Memorial Hospital, DK-2820 Gentofte, Denmark

S PRAMMING, $M D$, research fellow

B THORSTEINSSON, MD, research fellow

C BINDER, MD, chief physician

Rigshospitalet, State University Hospital, Department of Psychiatry, Copenhagen, Denmark

A THEILGAARD, DMSC, chief psychologist

E M PINNER, MA, psychologist

Correspondence to: Dr Pramming. relation between these and the blood glucose concentration is poorly defined. Nevertheless, we should not accept that asymptomatic biochemical hypoglycaemia is harmless without examining the functional consequences of these low blood glucose concentrations. Definition of a blood glucose value below which functional changes occur is therefore important. This might be a value either at which counter-regulatory hormones are released or at which cerebral function is affected. While the first of these has been extensively studied ${ }^{3.7}$ only scarce information is available about the second. ${ }^{8.10}$

We tested cognitive functioning in a group of insulin dependent (type I) diabetic patients at normal, subnormal, and hypoglycaemic blood glucose concentrations. Testing was also carried out immediately after correction of the hypoglycaemia.

\section{Subjects and methods}

Sixteen insulin dependent diabetic men agreed to participate in the hypoglycaemia study. A further six patients took part in a sham study. The two groups were comparable in age, duration of diabetes, insulin dose, body weight, and haemoglobin $A_{1 c}\left(H_{b} A_{1 c}\right)$ concentration (table I). All were prone to ketosis with minimal $\beta$ cell function (C peptide concentration $<0.1 \mathrm{nmol} / 1(<0.3 \mathrm{ng} / \mathrm{ml})$ after glucagon stimulation $)$ and had been treated with insulin from the time of diagnosis. One patient had proliferative retinopathy; none had protein detectable in urine (Albustix), raised serum creatinine concentration, symptomatic neuropathy, any psychiatric disease, or received drugs other than insulin. The studies were performed at the Steno Memorial Hospital and were approved by the regional scientific ethical committee. Informed consent was obtained from all patients.

\section{PROTOCOL}

Hypoglycaemia study - Patients were admitted to hospital 12 hours before the hypoglycaemia study. They omitted their evening dose of intermediate acting insulin and were treated in hospital with small subcutaneous doses of soluble insulin according to blood glucose concentrations, measured every second hour in order to avoid hypoglycaemia, before the study period. They fasted from midnight and remained recumbent throughout. At 0600 an intravenous insulin infusion with soluble highly purified porcine insulin (Velosulin, Nordisk Gentofte) was started. An antecubital catheter for blood sampling was placed in the contralateral arm and kept patent with heparinsaline. Figure 1 shows the study design. Blood was drawn every 10 minutes for blood glucose determination. The insulin infusion was adjusted according to bedside blood glucose determinations to produce steady blood glucose concentrations of $6,3,2$, and $6 \mathrm{mmol} / \mathrm{l}(108,54,36$, and $108 \mathrm{mg} / 100$ $\mathrm{ml}$ ) at test periods A, B, C, and D, respectively. Patients were told that they would be hypoglycaemic during one of the neuropsychological tests, but 
neither the actual blood glucose concentration nor the sequence of testing was known to them.

Sham study-Except for maintenance of a constant blood glucose concentration the protocol for the sham study was the same as for the hypoglycaemia study. The insulin infusion was adjusted to produce a constant blood glucose concentration of roughly $6 \mathrm{mmol} / 1$ throughout. presented verbally. This is a test of attention and short term memory. The score is the highest number of digits repeated correctly.

The tapping test measures psychomotor function. The subject presses a button repeatedly as fast as possible for 10 seconds using the dominant hand.

The score is the number of taps per minute.

The letter cancellation test is a shortened version of Bourdon's classical

TABLE I-Details of study groups. Values are means (ranges in parentheses)

\begin{tabular}{|c|c|c|c|c|c|}
\hline & $\begin{array}{l}\text { Age of } \\
\text { subjects } \\
\text { (years) }\end{array}$ & $\begin{array}{c}\text { Duration of } \\
\text { diabetes } \\
\text { (years) }\end{array}$ & $\begin{array}{l}\text { Insulin dose } \\
(\mathrm{IU} / \mathrm{kg} / \text { day })\end{array}$ & $\begin{array}{l}\text { Body weight } \\
\text { index }(\%)\end{array}$ & $\begin{array}{c}\mathrm{HbA}_{\mathrm{lc}} \\
(\%)\end{array}$ \\
\hline Hypoglycaemia study $(n=16)$ & $28(20-46)$ & $12(4-28)$ & $0.68(0.31-1 \cdot 27)$ & $97(76-120)$ & $8 \cdot 7(7 \cdot 2-10 \cdot 1)$ \\
\hline Sham study $(n=6)$ & $30(20-40)$ & $13(2-26)$ & $0.61(0.35-0.85)$ & $106(94-119)$ & $8 \cdot 5(6 \cdot 5-9 \cdot 4)$ \\
\hline
\end{tabular}

TABLE II-Blood glucose concentrations (mmol/l). Values are means (ranges in parentheses)

\begin{tabular}{|c|c|c|c|c|}
\hline & \multicolumn{4}{|c|}{ Neuropsychological test period } \\
\hline & A & B & $\mathrm{C}$ & $\mathrm{D}$ \\
\hline & \multicolumn{4}{|c|}{ Hypoglycaemia study } \\
\hline \multirow{3}{*}{$\begin{array}{l}\text { Difference in values between test periods (A-B, B-C, C-D) } \\
\text { Difeos }\end{array}$} & $6 \cdot 3(3 \cdot 9-7 \cdot 4)$ & $2 \cdot 9(2 \cdot 3-3 \cdot 3)$ & $1 \cdot 8(1 \cdot 5-2 \cdot 1)$ & $6 \cdot 1(4 \cdot 8-7 \cdot 6)$ \\
\hline & & 5) $\quad 1 \cdot 1$ & 4) $\quad-4 \cdot 3$ & $-5 \cdot 8)$ \\
\hline & \multicolumn{4}{|c|}{ Sham study } \\
\hline Blood glucose concentration & $7 \cdot 0(4 \cdot 8-8 \cdot 8)$ & $6 \cdot 5(4 \cdot 8-7 \cdot 9)$ & $6 \cdot 2(4 \cdot 7-7 \cdot 2)$ & $6 \cdot 0(4 \cdot 5-7 \cdot 0)$ \\
\hline
\end{tabular}

Conversion: SI to traditional units_Glucose: $1 \mathrm{mmol} / \mathrm{l} \approx 18 \mathrm{mg} / 100 \mathrm{ml}$

TABLE III-Results of all tests in neuropsychological test battery. Values are medians (ranges in parentheses)

\begin{tabular}{lccccc}
\hline & \multicolumn{5}{c}{ Neuropsychological test period (hypoglycaemia study) } \\
\cline { 2 - 5 } Test & A & B & C & D & Sham study \\
\hline Tapping (U) & $60(38-72)$ & $64(38-74)$ & $56(38-66)$ & $61(37-71)$ & $60(41-72)$ \\
Digit span (U) & $7(5-9)$ & $6(4-8)$ & $5(3-7)$ & $7(4-8)$ & $6(5-7)$ \\
Bourdon's test (U) & $363(198-582)$ & $377(180-514)$ & $324(97-509)$ & $414(162-600)$ & $339(162-562)$ \\
Categorisational test (U) & $8(2-14)$ & $6(3-12)$ & $5(1-9)$ & $8(3-12)$ & $7(2-15)$ \\
Trailmaking (s) & $136(82-297)$ & $135(92-262)$ & $192(50-300)$ & $124(57-257)$ & $135(65-290)$ \\
Story recall (U) & $13(6-17)$ & $11(6-16)$ & $11(2-14)$ & $12(8-17)$ & $11(6-17)$ \\
Serial sevens subtraction (s) & $42(14-82)$ & $44(17-110)$ & $48(31-300)$ & $32(15-66)$ & $35(16-85)$ \\
Time estimation (s) & $59(24-123)$ & $62(21-91)$ & $80(26-110)$ & $58(34-81)$ & $60(35-100)$ \\
\hline
\end{tabular}

^See text for definition of tests.

Before the sham study patients were told that they would be tested either during a constant blood glucose concentration or during hypoglycaemia

Analytical techniques-Mixed venous blood glucose concentration was measured using a glucose analyser (Yellow Spring Instruments), and blood from the same sample was later analysed in the laboratory by a glucose oxidase method. The mean variations between these two blood glucose samples during the four neuropsychological test periods were $0 \cdot 2,0 \cdot 1,0 \cdot 1$, and $0 \cdot 3 \mathrm{mmol} / 1(3 \cdot 6,1 \cdot 8,1 \cdot 8$, and $5 \cdot 4 \mathrm{mg} / 100 \mathrm{ml})$ respectively. The mean of these two values was therefore used. Glycosylated haemoglobin was measured as described.

\section{NEUROPSYCHOLOGICAL TESTS}

Owing to lack of previous research no published selection of appropriate tests was available. A test battery was therefore constructed consisting of well known tests of short duration, able to be administered at the bedside, sensitive to subtle changes in performance, and with little "practice effect" that might improve performance in subsequent tests. Four parallel sets of tests were constructed and applied in random order. The test battery served as a basis for analysing various psychological skills ranging from simple motor tasks to more complex problems in memory and control. All testing was conducted by the two psychologists (AT, EMP). To avoid any effect of difference in hemispheric dominance and sex only right handed men were included. Right handedness was tested according to Oldfield. ${ }^{12}$

Each set of tests lasted 20-30 minutes with at least 50 minutes between test periods.

Digit span-The digit span is a subtest from the Wechsler adult intelligence scale. ${ }^{13}$ The subject is asked to repeat digits in the sequence
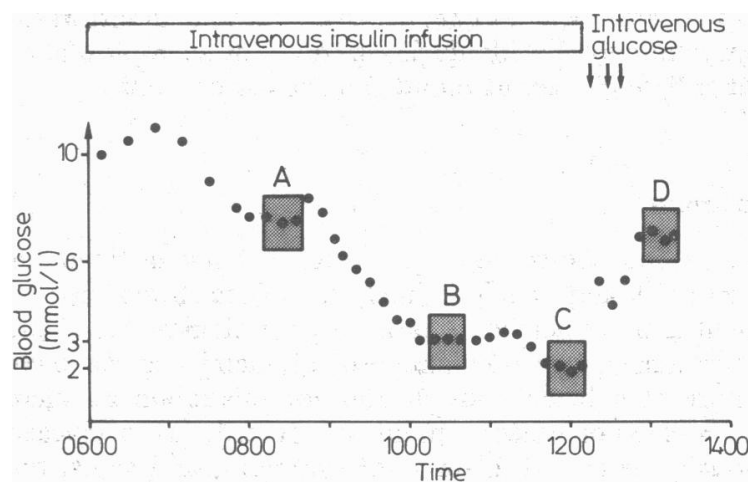

FIG 1-Hypoglycaemia study protocol and blood glucose concentrations $(-$ in one patient (case 9 ). Hatched areas A-D represent times of neuropsychological testing. Blood glucose concentration measured every 10 minutes.

Conversion: $S I$ to traditional units-Glucose: $1 \mathrm{mmol} / \mathrm{l} \approx 18 \mathrm{mg} /$ $100 \mathrm{ml}$.

test. ${ }^{14}$ Subjects are presented with unbroken rows of letters and must cancel $a, b, n$, and $p$ as fast as possible for three minutes. The test requires rapid discrimination of details and measures attention and distractibility. The score is the number of letters read and the number of errors.

In the categorisational test the subject is asked to write down as many items 
of a specific category as possible within one minute. The test measures ideational fluency and is scored as the number of relevant items. ${ }^{15}$

In trail making the subject must connect letters (a-1) with numbers (1-12) alternately in correct order over three minutes. The test calls for attention, visual scanning, and planning and is scored as the number of seconds needed to complete the task.

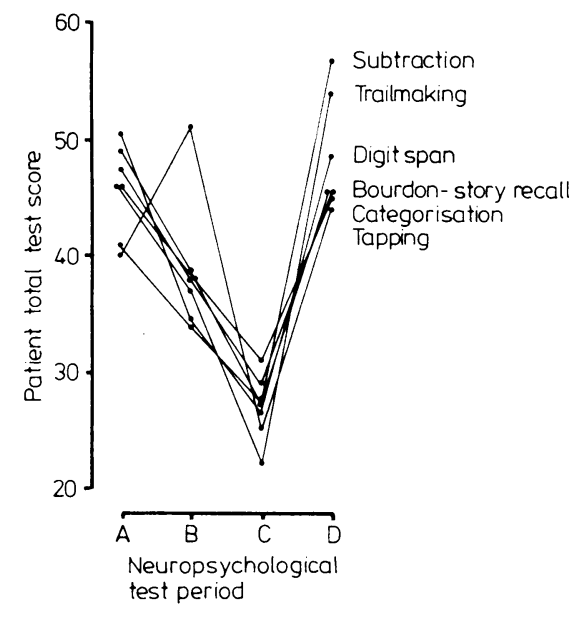

FIG 2-Patient total neuropsychological test scores (see text) in the four test periods. Mean blood glucose concentrations at periods $\mathrm{A}, \mathrm{B}, \mathrm{C}$, and $\mathrm{D} 6 \cdot 3,2 \cdot 9,1 \cdot 8$, and $6 \cdot 1 \mathrm{mmol} / \mathrm{l}(113 \cdot 5,52 \cdot 3$, $32 \cdot 4$, and $109 \cdot 9 \mathrm{mg} / 100 \mathrm{ml}$ ) respectively (table II).

Story recall tests short term memory. A connected narrative consisting of 18 units is read slowly and immediately afterwards the subject is asked to recall as much as possible. The score is the number of units recalled.

Serial sevens subtraction-In this test the subject counts backwards from $100,99,98$, or 97 in sevens. The score of this concentration test is the number of errors and time taken.

\section{EVALUATION OF PERFORMANCE}

All tests give quantitative results which cannot be compared directly. Results were therefore evaluated by rank analysis. For each patient the results in the four test periods were compared and ranked 1 to 4 , where 4 denotes the best results; when ranking, ties were taken into account. Ranked test data were then analysed with regard to the patients as well as to the tests as patient total neuropsychological test score (total rank sum for a given patient at a given test period, calculated as the sum of each of the ranks of the seven tests) and test total score (total rank sum for a given test at a given test period, calculated as the sum of each of the ranks of the 16 patients).

\section{ESTIMATION OF ELAPSED TIME}

Patients were asked to estimate the passage of one minute without the use of a clock or counting. The score was the number of seconds by which the subject overestimated or underestimated the true duration.

\section{QUESTIONNAIRE}

Based on the most common symptoms reported during hypoglycaemia ${ }^{16} \mathrm{a}$ list of 14 symptoms was presented to the patients at the start of each test period. Patients scored the intensity of these symptoms from zero to 4 and total symptom scores were then calculated. Patients were also asked whether they thought their symptoms, if any, were due to hypoglycaemia.

\section{STATISTICAL ANALYSIS}

Results were analysed by the Wilcoxon-Pratt paired rank sum test, $p<0.05$ being taken as statistically significant. Unless otherwise stated data are presented as means and one standard error of the mean (SEM).

\section{Results}

\section{BLOOD GLUCOSE CONCENTRATIONS}

Table II shows the mean blood glucose concentration at each test period and the difference in concentrations between consecutive test periods. The degree of control of the blood glucose concentrations, calculated as (actual mean/desired value) $\times 100$, was $105($ SEM 16)\%, $96(8) \%, 92(10) \%$, and 102 $(15) \%$ in the four test periods respectively. Stability of the concentration in each test period (coefficient of variation of blood glucose during the test periods) was $7(3) \%, 8(4) \%, 7(4) \%$, and $6(3) \%$ respectively.

\section{NEUROPSYCHOLOGICAL TEST RESULTS}

Table III gives the results of each test in the four test periods, and figure 2 the patient total neuropsychological test scores for all patients. The total score deteriorated in 12 patients between test periods $A$ and $B(p<0.02)$. The four patients who improved had the same blood glucose concentration at period B as the rest of the patients. They were, however, characterised by being the ones who improved their total test scores the most between the first and last test periods, suggesting a submaximal performance at the first test period. From period $B$ to period $C$ all but one of the scores deteriorated $(\mathbf{p}<0.01)$. After restoration of a normal blood glucose concentration (period D) the score improved in all patients $(p<0 \cdot 01)$. There was no significant difference between scores in the first and last test periods.

Test total scores (fig 3) - Between periods A and B the scores of all but one test (tapping) fell. Except for the digit span test $(p<0.05)$ no single test result deteriorated significantly. The fall in the overall test scores between periods $A$ and $B$ was not significant $(p=0 \cdot 22)$ owing to the relatively high rank of improvement in the tapping test. Between periods $\mathrm{A}$ and $\mathrm{C}$ a fall in all single test scores $(\mathrm{p}<0.05)$ - but not the tapping test score, which fell significantly between periods $B$ and $C-$ as well as in the overall score $(p<0.01)$ was observed. All individual scores $(p<0.05)$ and the overall score $(p<0.01)$ improved between periods $C$ and $D$. There was no significant difference between scores at periods $\mathrm{A}$ and $\mathrm{D}$.

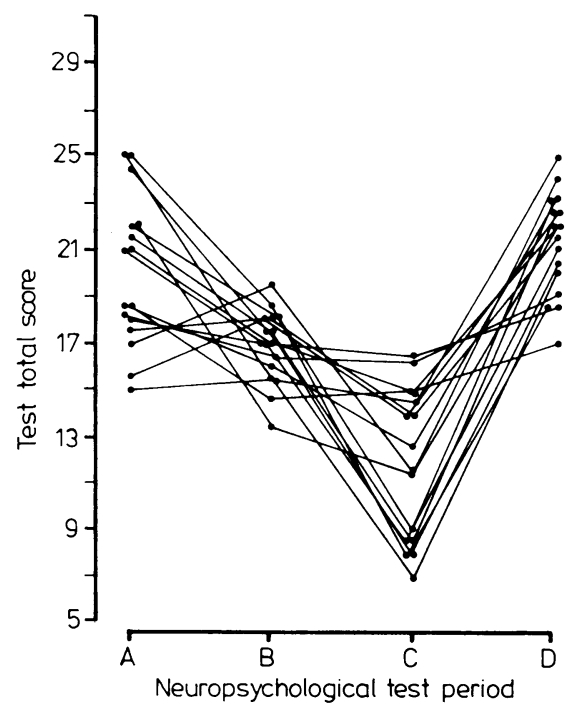

FIG 3-Test total scores (see text) in the four periods.

\section{ESTIMATION OF ELAPSED TIME}

Patients' estimation of elapsed time (table III) altered during test period C, so that the "inner clock" went significantly more slowly than at periods A, $\mathrm{B}$, and $\mathrm{D}($ all $\mathrm{p}<0 \cdot 05)$.

\section{SHAM STUDY}

There was no significant difference in blood glucose concentrations among the four neuropsychological test periods in the sham study (table II). Blood glucose concentrations in periods A and D did not differ significantly 
from those in the hypoglycaemia study at those times. The neuropsychological test scores in period A did not differ significantly between the two studies. Neuropsychological performance did not differ in the four test periods during the sham study. Table III gives the average result of all tests in the sham study.

\section{QUESTIONNAIRE}

In the hypoglycaemia study the total symptom score of hypoglycaemia showed no significant difference between test periods $\mathrm{A}$ and $\mathrm{B}$. The score was increased at period $C$ compared with at periods $A$ and $B$, and decreased between periods $\mathrm{C}$ and $\mathrm{D}$ (all $\mathrm{p}<0.05)$. The symptom score was significantly higher at test period $D$ than at period $A(p<0.05)$. None of the patients reported symptomatic hypoglycaemia at period $A$ or $B$. Twelve of the 16 patients reported symptomatic hypoglycaemia at period $C$ and one at period D.

No significant changes in total symptom scores were observed during the four test periods in the sham study. One patient, however, reported symptomatic hypoglycaemia at test periods A and B (mean blood glucose concentrations $8 \cdot 1$ and $7 \cdot 9 \mathrm{mmol} / 1$ (146 and $142 \mathrm{mg} / 100 \mathrm{ml}$ ) respectively).

\section{Discussion}

As might be expected, lowering the blood glucose concentration to below $2 \mathrm{mmol} / \mathrm{l}(36 \mathrm{mg} / 100 \mathrm{ml})$ was accompanied by cognitive dysfunction in all patients. Four, however, failed to recognise this as hypoglycaemia, though two had an increased score for the relevant symptoms. Despite blood glucose concentrations around $1.5 \mathrm{mmol} / \mathrm{l}(27 \mathrm{mg} / 100 \mathrm{ml})$ three patients showed no clinical signs of hypoglycaemia, though the observers may have been biased by knowing the actual values. Unexpectedly, neuropsychological performance deteriorated at a blood glucose concentration just below $3 \mathrm{mmol} / \mathrm{l}(54 \mathrm{mg} / 100 \mathrm{ml})$ in 12 of the 16 patients, though none perceived this state as hypoglycaemia. Symptoms and signs thus appear to be unreliable indices of neuroglycopenia. If we depend on symptoms and signs as the only indicators of hypoglycaemia we thereby accept intermittent cerebral dysfunction as normal in insulin treated diabetic patients. Patients who recognised hypoglycaemia did so only at low blood glucose concentrations $(1 \cdot 5-$ $2 \cdot 1 \mathrm{mmol} / 1 ; 27 \cdot 0-37 \cdot 8 \mathrm{mg} / 100 \mathrm{ml}$ ). In some patients cerebral dysfunction was pronounced at these values and, combined with reduced reaction time and diminished attention, ${ }^{810}$ this might influence their ability to avert severe hypoglycaemic episodes. The claim that relatives are often able to detect impending hypoglycaemia before the patient ${ }^{1617}$ is in keeping with our findings, since cerebral function seems to alter before symptoms appear.

The question remains whether hypoglycaemia affects overall brain function or is confined to specific functions. That the outcome of all but one test (tapping) showed gradual deterioration with decreasing blood glucose concentration favours intermittently diminished "attention" as the main manifestation of cerebral dysfunction. A blood glucose concentration of about $2 \mathrm{mmol} / \mathrm{l}$ affected all tests significantly compared with initial results, and no single test was more sensitive than any other to a blood glucose concentration of around $3 \mathrm{mmol} / \mathrm{l}$. Nevertheless, since the tapping test, representing the most simple function of all the tests in the battery, was the least sensitive to a reduction in blood glucose concentration, it might be interpreted as a correlate in everyday life of relatively undisturbed psychomotor function at this "subnormal" blood glucose value. The outcome of tests such as trailmaking and subtraction suggest that the performance of everyday tasks that entail planning and control will suffer even at a subnormal blood glucose concentration of around $3 \mathrm{mmol} / \mathrm{l}$, which is not usually considered to be hypoglycaemic.

At low blood glucose concentrations (test periods $\mathrm{B}$ and $\mathrm{C}$ ) we found that much prompting and encouragement were needed compared with during the normoglycaemic periods (A and D). The patients were often well aware of the character of the test and the performance required but their executive functions were negatively affected. ${ }^{18}$ This may well reflect a phenomenon often observed in diabetic patients-namely, that despite being aware of their hypoglycaemic state and knowing how to remedy it they are unable to execute the necessary action. The more a task makes demands on the executive functions, the more important becomes the part played by the frontal lobes responsible for planning, programming, and controlling actions. ${ }^{19}$ Possibly the frontal lobes are more sensitive to hypoglycaemia than other cortical regions.

There is no uniformly accepted definition of the hypoglycaemic level in insulin treated diabetics. Some define it as the blood glucose concentration at which symptoms and signs usually develop-that is, around $2 \mathrm{mmol} / \mathrm{l}(36 \mathrm{mg} / 100 \mathrm{ml})$ in normal subjects. ${ }^{201}$ Others define the hypoglycaemic level in terms of "normality"-for example, below the lower limit of the normal blood glucose range. It is questionable whether these cut off values, obtained in nondiabetic subjects, are appropriate when dealing with diabetic patients taking insulin. These patients depend entirely on their brain functions when needing to avoid the dangers of too low blood glucose concentrations.

Although the changes in cerebral function seemed reversible in this study, we cannot say whether persistent damage might result, especially after years of repetitive episodes. Functional cerebral changes may also have implications for the everyday life of diabetic patients-for example, affecting their ability to drive a car, work at a machine, pass an examination, or make important decisions. A more logical approach might therefore be to define the hypoglycaemic concentration at which brain function deteriorates. We suggest that concentration to be roughly $3 \mathrm{mmol} / \mathrm{l}(54 \mathrm{mg} / 100 \mathrm{ml})$, below which cognitive function deteriorates in most patients. This concentration is higher than that at which symptoms and signs, if any, appeared in our patients but accords with the value $(3.3$ $\mathrm{mmol} / \mathrm{l} ; 59.5 \mathrm{mg} / 100 \mathrm{ml}$ ) leading to a counter-regulatory hormonal response. ${ }^{2223}$ If a lower limit for acceptable blood glucose concentrations of the proposed magnitude is generally agreed on scrupulous home blood glucose monitoring should be the rule, symptoms of hypoglycaemia being considered only as supplementary to the blood glucose measurements.

\section{References}

1 Siperstein MD, Foster DW, Knowles HC Jr, Levine R, Madison LL. Control of blood glucose and diabetic vascular disease. $N$ Engl 7 Med 1977;296:1060-3.

2 Unger HR. Meticulous control of diabetes. Benefits, risks and precautions. Diabetes 1982;31 479-83.

3 Bolli G, DeFeo P, Campagnucci P, et al. Important role of adrenergic mechanisms in acute glucose counter-regulation following insulin-induced hypoglycemia in type 1 diabetes. Diabetes 1982;31:41-7.

4 Gerich JE, Cryer PE, Rizza RA. Hormonal mechanisms in acute glucose counter-regulation: the relative roles of glucagon, epinephrine, norepinephrine, growth hormone and cortisol. Metabolism 1980;29:1164-75.

5 Santiago JV, Clarke WL, Shah SD, Cryer PE. Epinephrine, norepinephrine, glucagon and growth hormone release in association with physiological decrements in the plasma glucose growth hormone release in association with physiological decrements in the plasma
concentration in normal and diabetic man. 7 Clin Endocrinol Metab 1980;51:877-83.

6 Cryer PE. Glucose counter-regulation in man. Diabetes 1981;30:261-4.

7 DeFronzo RA, Hendler R, Christensen NJ. Stimulation of counter-regulatory hormonal responses in diabetic man by fall in glucose concentration. Diabetes 1980;29:125-31.

8 Smith-Holmes C, Hayford JT, Gonzales JL, Weydert JA. A survey of cognitive functioning a different glucose levels in diabetic persons. Diabetes Care 1983;6:180-4.

9 Flender J, Lifshitz. F. The effects of fluctuations of blood glucose levels on physiological performance of juvenile diabetics. Diabetes 1976;25:334.

10 Herold KC, Polonsky KS, Cohen RM, Levy J, Douglas F. Variable deterioration in cortical function during insulin-induced hypoglycemia. Diabetes 1985;34:677-85.

11 Svendsen PAa, Christiansen JS, Søgaard U, Welinder BS, Nerup J. Rapid changes in chromatographically determined haemoglobin $A_{\mathrm{lc}}$ induced by short term changes in glucose concentragraphically determined haemoglobin A
tions. Diabetologia 1980;19:130-6.

12 Oldfield RC. The assessment and analysis of handedness. Neuropsychologia 1971;9:97-113.

13 Wechsler O. Wechsler adult intelligence scale. New York: The Psychological Corporation, 1955.

13 Wechsler O. Wechsler adult intelligence scale. New York: The Psychological Corpor
14 Lezak MB. Neuropsychological assessment. Oxford: Oxford University Press, 1976.

15 Trench JW, Ekstrom RB. Manual for kit of reference tests for cognitive factors. Princeton: NJ Educational Testing Service, 1963

16 Goldgewicht C, Slama G, Papol A, Tchobroutsky G. Hypoglycaemic reactions in 172 type 1 (insulin-dependent) diabetic patients. Diabetologia 1983;24:95-9.

17 Sommerville JM, McLawn EH, Hewie EY. Early warning symptoms of hypoglycemia in ambulant diabetics [Abstract]. Diabetologia 1981;20:675.

18 Pribram K, McGuinness A. Arousal, activation and effect in the control of attention. Psychol Rev 1975;82:116-49.

19 Luria AR. Higher cortical functions in man. London: Tavistock Publications, 1966.

20 Marks V, Rose FC. Hypoglycaemia. 2nd ed. London: Blackwell, 1980.

21 Amiel SA, Simonsen DC, DeFronzo RA, Tamborlane WV, Sherwin RS. The rate of glucose fall does not determine the counterregulatory hormone response to hypoglycaemia. Diabetologia 1984;27:251A.

22 Bennett T, Gale EAM, Green JH, MacDonald IA. The influence of insulin-induced hypoglycaemia on thermo-regulation. F Physiol (Lond) 1979;308:26p.

23 Boli GB, Gottesman IS, Campbell PJ, Haymond MW, Cryer PE, Gerich JE. Glucose counterregulation and warning of insulin in the Somogyi phenomenon (posthypoglycemic hyperglycemia). N Engl f Med 1984;311:1214-9.

(Accepted 13 December 1985) 